\title{
La legitimidad de la actividad jurisdiccional después de la emisión de una sentencia ${ }^{1}$
}

\author{
https://doi.org/10.21830/9789585284883.05
}

\author{
Manuel Bermúdez-Tapia \\ Universidad Privada San Juan Bautista \\ Carolina Pedraza Mariño ${ }^{3}$ \\ Ingrid Yuliana Arango Calderón ${ }^{4}$ \\ Escuela de Aviación del Ejército
}

\section{Introducción}

Uno de los problemas más relevantes de la evaluación del sistema de impartición de justicia en Colombia está vinculado a la nula revisión de la legitimidad del desarrollo de un servicio público de tanta importancia en el ámbito nacional. En consecuencia, surge un tema complementario, referido a que no se ha evaluado correctamente el costo económico que implica el servicio de la

1 Este capítulo hace parte de los resultados del proyecto de investigación "Perspectivas en Derechos Humanos y Derecho Internacional Humanitario para el Ejército Nacional de Colombia" del Grupo de Investigación en Aviación Militar de la Escuela de Aviación del Ejército, registrado con el código COL0077618 y categorizado en C por Minciencias. Los puntos de vista pertenecen a los autores y no reflejan necesariamente los de las instituciones participantes.

2 Abogado (magna cum laude) de la Pontificia Universidad Católica del Perú. Magíster en Derecho y PhD en Derecho por la Pontificia Universidad Católica de Argentina. Profesor-investigador de la Universidad Privada San Juan Bautista y profesor de la Facultad de Derecho de la Universidad Nacional Mayor de San Marcos. Orcid: http://orcid.org/0000-0003-1576-9464 - Contacto: manuel.bermudez@upsjb. edu.pe

3 Capitán en el Ejército Nacional de Colombia. Especialista en Ciencias Militares para el Planeamiento, Centro de Educación Militar, Colombia. Profesional en Ciencias Militares y profesional en Administración Logística, Escuela Militar de Cadetes "General José María Córdova”, Colombia. Investigadora de la Escuela de Aviación del Ejército, Grupo de investigación en Aviación Militar. Orcid: https://orcid.org/0000-0001-5055-3154 - Contacto: carolina.pedraza@buzonejercito.mil.co

4 Capitán en el Ejército Nacional de Colombia. Especialista en Ciencias Militares para el Planeamiento, Centro de Educación Militar, Colombia. Profesional en Ciencias Militares y profesional en Administración Logística, Escuela Militar de Cadetes "General José María Córdova", Colombia. Investigadora de la Escuela de Aviación del Ejército, Grupo de investigación en Aviación Militar. Orcid: https://orcid.org/0000-0002-5995-9262 - Contacto: ingrid.arango@buzonejercito.mil.co 
administración e impartición de justicia en el país. De este punto, se deriva otro aspecto a evaluar: la política de Estado, política pública o política de gobierno, con respecto a la cual no se comprende por qué no se han identificado los elementos que deben ser objeto de examen para determinar el verdadero costo del servicio estatal y poder así establecer eventuales soluciones (Miron, 2019).

Ante lo descrito, observamos que no se logra evaluar correctamente la real dimensión del servicio y, por ello, se genera nuestra posición que incide en la "legitimidad de esta función estatal", la cual genera una serie de situaciones derivadas, que van desde la misma evaluación de la institucionalidad de las entidades que forman parte de este servicio público hasta la propia relación democrática entre ciudadanía y Estado respecto al contrato social.

El contexto de negligencia y desidia en la gestión del servicio público más importante en el país es una característica que se agudiza en determinados ámbitos sensibles a la población, como las especialidades jurisdiccionales de familia y penal, donde los conflictos familiares y sociales están colapsando de una manera mucho más profunda la propia institucionalidad del Estado, en lo que tiene que ver con las instituciones que imparten justicia.

Históricamente, este punto representa el mayor elemento negativo expresado por la ciudadanía en cuanto a su relación con el Estado, y ha cobrado mayor agudeza en los últimos años, porque los niveles de violencia social y de corrupción en el aparato público llegan a puntos insostenibles.

\section{El conflicto social en evaluación}

En la evaluación de un expediente judicial, las instituciones que imparten justicia suelen tomar como elemento preponderante de referencia la sentencia, como si esta fuera la continuación del proceso de producción del derecho (Rodríguez Boente, 2003, p. 551). No se toma en cuenta que la sentencia no se ejecuta de forma automática, y por ello la mayoría de las sentencias no logra incluir mecanismos de fiscalización (i), de control institucional (ii) o de represión o imposición de sanciones en caso de que no se cumpla lo dispuesto (iii).

La mejor referencia para evaluar una crítica de este punto se evidencia en la forma en que se desarrollan las especialidades jurisdiccionales de familia 
(respecto de los casos de violencia familiar) y penal (respecto de los casos vinculados a corrupción). En la jurisdicción vinculada con el ámbito familiar, por ejemplo, cuando se observa un conflicto sociofamiliar judicializado entre personas que habían conformado una relación (matrimonial, convivencial, concubinal o temporal) o en una familia en una situación de crisis, se deben detallar algunos factores que inciden en el trámite del proceso judicial. Dichos factores señalan periodos temporales que resultan muy específicos, porque "identifican” elementos y características comunes:

a. El contexto preprocesal de las partes en conflicto, que al ser muy subjetivo limita toda situación prejudicial de solución, factor que limita la conciliación o mediación que pudiera plantearse (López \& Pérez, 2004, p. 44). Las partes, entonces, no asumen objetivamente los tiempos, costos ni derechos de la contraparte; tampoco asumen un verdadero compromiso en la solución de su conflicto, principalmente, porque este tiene una naturaleza subjetiva.

b. Elementos jurisdiccionales que se observan en el trámite del expediente judicial.

c. Elementos jurisdiccionales de carácter administrativo que están vinculados con el modo en el cual se ejecuta una sentencia judicial (Pérez Martín, 2009, p. 51).

Una circunstancia semejante se observa en el ámbito jurisdiccional penal, principalmente, porque los Estados latinoamericanos no han logrado identificar el método de control de la sentencia condenatoria para así determinar su nivel de eficacia con respecto a la obligación estatal de rehabilitar al condenado.

La razón de esta situación es que la doctrina, en lo procesal y en la mayoría de las especialidades jurídicas, no han enfatizado elementos teóricos aplicables a la etapa posterior a la emisión de la sentencia (Pérez del Blanco, 2003, p. 146), sobre la base de la presunción de que la resolución judicial —la sentencia- se cumple per se.

No se toma en cuenta el contexto "administrativo" de ejecutar la decisión judicial, porque la sentencia no ha logrado finalizar el conflicto material que dio inicio al proceso judicial. Por tal razón, se hace referencia al contexto familiar 
evaluado en un expediente judicial, en el que la sentencia materialmente no logrará finalizar el contexto negativo que las partes procesales exponen en su ámbito personal y familiar (Quintero Cordero, 2020).

Este elemento se amplifica en los casos judicializados en la especialidad familiar y penal, en particular, en el contexto de la atención a las víctimas, que no logran visualizar algún efecto positivo en la sentencia. En este sentido, en el ámbito penal, las víctimas de delitos contra la libertad sexual o indemnidad sexual prácticamente se encuentran en un contexto de victimización provocada por el propio Estado, porque a la lesión del derecho ya generado, a la tutela de sus expectativas, intereses y derechos, no se les ha generado ninguna atención.

En el ámbito familiar, podemos señalar que se generó una situación de crisis, en la que las partes en contradicción no hacen públicas sus diferencias. Crisis que ha provocado un conflicto (donde las partes son antagónicas y tal situación es exteriorizada), pero al no reducirse los niveles de violencia en la comunicación, el problema familiar se judicializa y no se limita a un único expediente judicial, por cuanto es característico que surjan otros procesos judiciales derivados, complementarios o paralelos, que solo amplían el contexto de relaciones contradictorias entre las partes procesales.

Esta afirmación se sustenta sobre la base de la evaluación de lo más común en el ámbito jurisdiccional familiar: casos como "alimentos", "tenencia o régimen de visitas" y "violencia familiar", entre otros, no logran ser solucionados en el "expediente judicial", porque las partes, a pesar de los alcances de una sentencia, siguen involucradas en un "conflicto" familiar que supera en lo temporal el periodo del "proceso judicial” (Peña et al., 2019, pp. 773-795). Un error que lamentablemente provoca una mayor crisis en el ámbito social y que extiende los efectos negativos de una visión parcial y limitada del verdadero problema en ciernes.

En el contexto judicial penal, las víctimas suelen tener inconvenientes en la aceptación de los mecanismos de "terminación anticipada del proceso": (i) en la "pena" impuesta en la sentencia condenatoria, (ii) en la cuantificación de la "reparación civil", (iii) en el mismo contexto de la referencialidad de la administración de los "beneficios penitenciarios" y (iv) en que la víctima prácticamente asume una segunda situación gravosa, lo que la convierte en una "víctima estructural". 


\section{El sistema judicial en el ámbito de la evaluación de conflictos entre partes procesales y partes involucradas en el conflicto}

Durante los últimos veinte años, la especialidad jurisdiccional con mayor movimiento de expedientes y actuaciones judiciales en la región latinoamericana ha sido la de familia, tanto por la atención de casos de violencia familiar como de conflictos familiares específicos (filiación, alimentos, tenencia, violencia familiar, etc.). El gran inconveniente observado en este ámbito es el negligente manejo del "conflicto familiar" por parte del legislador, lo cual resulta amplificado por el magistrado, porque no se logra evaluar correctamente el objeto de estudio en el trabajo jurisdiccional.

El conflicto familiar es asumido como un "conflicto de intereses" o un "conflicto de derechos" entre las partes procesales, sin tomar en cuenta la naturaleza de las posiciones de las partes, que no necesariamente son "partes procesales". Es por ello que se desconoce a los "terceros" intervinientes en el conflicto, cuyo caso más notorio es la situación invisible del "hijo" de una pareja en crisis en el trámite de un expediente judicial. Ante esta realidad, conviene detallar algunos elementos referenciales.

\section{a. El análisis de los "tiempos" en la evaluación del conflicto familiar que se judicializa}

En esta especialidad, resultan identificables tres periodos de tiempo vinculados al análisis del "conflicto familiar". Estos tiempos nos permiten identificar patrones específicos en las relaciones de pareja o relaciones familiares en crisis, lo cual está vinculado, sobre todo, al contexto en el cual se desarrollan los ámbitos "íntimos", "privados" y "públicos" del "conflicto" que se va desarrollando y que no siempre adquiere la misma condición o evaluación en las partes involucradas.

\section{b. La etapa previa al proceso judicial: el origen del conflicto}

En este periodo, las "partes procesales" son identificadas en función del "conflicto material" que provoca el surgimiento de las personas con "legitimidad para obrar" e "interés para obrar". En esencia, esta etapa permite 
identificar cómo se ejecutará el proceso judicial, por cuanto determinará las facultades y condiciones que deberán tener la "parte demandante" y la "parte demandada", elementos esenciales para que se desarrolle un proceso judicial en el ámbito civil o familiar. Igualmente se configurará el "contexto" sobre el cual se desarrolla el conflicto de intereses que esencialmente se vincula con el origen de la controversia entre dos partes.

Tal controversia está vinculada al ámbito de la determinación de "derechos" o de la prestación de "obligaciones" de cada parte, los cuales serán expuestos con base en dos elementos referenciales: lo regulado normativamente en alguna norma jurídica y las condiciones en las cuales las partes han desarrollado sus relaciones interpersonales. Esto último está vinculado a la "línea temática” del conflicto, la cual configura tanto la especialidad como el órgano competencial en función del contexto del conflicto desarrollado.

Sin embargo, en el contexto familiar, a diferencia de otras jurisdicciones, el "conflicto" no siempre da origen a un proceso judicial. Esta situación se deben a varias causas.

i. Casos en los que las propias partes optan por no desarrollar ningún conflicto judicial, dado que la "autonomía de voluntades" opera en un gran sentido y restringe el contexto negativo del conflicto y la solución está mucho más próxima a los intereses de las partes en conflicto. De esta situación es que surgen los contextos de negociación o conciliación entre las partes.

ii. Casos en los cuales el conflicto familiar se soluciona con la limitación de una parte, que acepta las condiciones de una "solución" aun en detrimento de sus propios intereses.

En este tipo de situaciones, las partes están en contradicción, pero se asume una posición "favorable" ante el contexto de sobrellevar un proceso judicial, por razones económicas, temporales y personales. Este caso explica el contexto en el cual las "conciliaciones" que usualmente se suscriben en los Centros de Conciliación reproducen "acuerdos" sumamente incongruentes con la realidad de las partes en conflicto y contienen elementos regulatorios imposibles de ser cumplidos en forma sostenida en el tiempo.

iii. Casos en los cuales, luego de un contexto negativo, se mantiene la opción de no ejecutar ninguna acción judicial, lapso identificado 
como "periodo de procrastinación", principalmente a raíz de la propia decisión de una de las partes, por lo general, la más perjudicada con la situación.

Esto explica el contexto (general) en el cual una "madre" no entabla una demanda por "alimentos" y "atrasa" la ejecución de este recurso judicial en defensa de su propio hijo, porque su motivación no ha tenido un fundamento legal.

La motivación personal en estos contextos es sumamente complicada de establecer y responde más a razones personales de quien se ha sentido afectado por una acción de una contraparte, generalmente la pareja o un familiar con quien se tiene un conflicto sobre algún derecho o una obligación que aún no está precisada respecto de su determinación y cumplimiento.

iv. Casos de desconocimiento de la normatividad a ser aplicada a la evaluación del conflicto. Este factor es un referente en todas las especialidades judiciales debido al desconocimiento del derecho, que perjudica, en especial, a la parte más débil del conflicto.

Dicho desconocimiento no es absoluto, pero debe vincularse con un contexto mucho más amplio que el de la evaluación legal, porque en este punto se asume el costo económico que implica la tutela de un derecho o la formulación de una pretensión en el ámbito jurisdiccional.

Igualmente, el análisis del costo de oportunidad y la evaluación del costo humano en la ejecución de un proceso judicial es un factor que no es tomado en cuenta en el ámbito institucional, pero sí es evaluado en el ámbito de las personas que se ven inmersas en un conflicto familiar.

El punto final nos permite detallar las razones por las cuales la intervención del Poder Judicial, el Ministerio Público o la propia Policía no se registra en las etapas iniciales del conflicto familiar: las partes en conflicto aún no logran determinar su posición final (legal, familiar, social o económica) frente a la contraparte. 


\section{c. La etapa del proceso judicial}

En esencia es cuando se formula una demanda en contra de una persona sobre la cual existe un "conflicto de intereses" — conforme es detallado tanto en los Títulos Preliminares del Código Civil (artículo III) como en el Código Procesal Civil (artículo III) — o se genera una denuncia que detalla la ejecud ción de un acto que es considerado "típico y antijurídico", sobre la cual se determinará una pena, conforme al Título Preliminar del Código Penal (artículo II), en el caso de la normatividad peruana.

El estudio de las principales normas aplicables a los procesos judiciales nos permite identificar que más allá de la determinación de las "partes en conflicto", prima el "marco normativo y regulatorio" en el cual se desarrolla un proceso judicial que en principio finaliza con la imposición de una sentencia. Bajo este parámetro, todo "tipo de proceso" o procedimiento en el ámbito jurisdiccional se debe considerar como equivalente entre sí, pues, en razón de la determinación de la sentencia como "cosa juzgada”, el trámite del proceso es seguido por las partes.

En esta etapa es donde se identifican:

i. Los elementos que conforman el "petitorio" y los "argumentos de defensa" de las partes procesales.

En el ámbito jurisdiccional de familia, las pretensiones suelen tener un carácter subjetivo que normalmente no se relaciona con el contexto jurídico que debería "vincularlo" al trámite de un expediente judicial.

ii. La exclusión de las personas que no son "parte procesal" del desarrollo del proceso judicial y su referencialidad como "tercero" en el desarrollo del mismo.

Un punto en particular que eleva el contexto de violencia social entre aquellas personas que, a pesar de formar parte del conflicto familiar, no logran participar en forma activa de un expediente judicial.

iii. La presentación y actuación de "medios probatorios", lo que implica la ejecución de una actividad probatoria y de evaluación en contradicción por parte de las partes del proceso. 
iv. La fundamentación de la decisión jurisdiccional con base en los elementos expuestos anteriormente.

Hasta esta instancia, el ámbito de la doctrina es unánime y no existen elementos contradictorios, por cuanto la "sentencia" en esencia debería resolver un conflicto de intereses o determinar la sanción de un hecho delictivo respecto de los asuntos de las áreas temáticas evaluadas como referenciales para este acápite.

\section{d. La etapa de la ejecución de la sentencia}

Lo detallado en el punto precedente, en particular en lo contenido en el último párrafo, es cuestionado en esta parte, principalmente porque:

1. En el ámbito jurisdiccional civil del ámbito no patrimonial se puede observar:

i. En casos de interdicción, las partes en conflicto no siempre "desarrollan" relaciones interpersonales pacíficas.

ii. En casos de sucesiones intestadas, las partes no logran "resolver" el contexto de la "división y partición" de la "masa hereditaria".

2. En el ámbito jurisdiccional de familia, las partes en conflicto no logran cumplir con las disposiciones judiciales, situación que se evidencia en:

i. En casos de alimentos, porque se genera un proceso judicial en la vía penal, al acreditarse la "omisión de asistencia familiar".

Surge un severo cuestionamiento a la práctica jurisdiccional que ha desarrollado el proceso de cobro de alimentos, que permite evidenciar que el "sistema" es defectuoso, porque en esencia los alimentos son un "derecho fundamental", y cuando el juez que determina que su sentencia no se cumple solicita la intervención del órgano jurisdiccional penal, evidencia su propia ineficiencia.

Otro defecto del "sistema jurisdiccional", principalmente en función de lo dispuesto por la ley, está vinculado con el hecho material de que los procesos judiciales que evalúan la contradicción a la "pensión de alimentos" impuesta en estos procesos 
deben ser cuestionados en un segundo proceso. Debido a esto, el periodo de desarrollo de la "acción procesal" a cargo de quien esté obligado a prestar alimentos provoca un contexto negativo en su propio ámbito individual.

ii. En casos de regulación de "tenencia o visitas", las partes suelen no cumplir estas disposiciones judiciales, en mérito principal a una posición subjetiva ante la contraparte.

En esencia, la partes ejecutan actos que no son justificados o son justificables en términos objetivos, porque el principal elemento de su acción está vinculado a un contexto subjetivo, sobre el cual el derecho y la sentencia prácticamente no pueden "incidir".

iii. En casos de violencia familiar, se ha acreditado que las partes pueden seguir manteniendo una relación afectiva aun a pesar del registro de hechos de violencia.

Basta con observar los alcances del artículo 356 del Código Civil para analizar que, incluso en casos de "trámite" de un proceso de divorcio, las partes pueden "solucionar" sus conflictos interpersonales conforme a lo detallado en el artículo 346 del Código Civil.

Por otra parte, en estos ámbitos, cuando se determina un "tratamiento psicológico", las partes en conflicto no saben "cómo se desarrolla este", por cuanto su determinación no es judicial sino "clínica", y las reglas que se emplean para evaluar "el periodo", la "cuantificación o evaluación del tratamiento", o "las condiciones en las cuales se desarrolla el tratamiento" no son precisadas en forma preliminar a su regulación.

De este modo, la regulación del modo en el cual se desarrollan las medidas jurisdiccionales resultan imprecisas y permiten un alto grado de discrecionalidad en personas ajenas al ámbito jurisdiccional. Debido a esto, el contexto preliminar de conflictividad aumenta, lo que explica las razones por las cuales las partes involucradas en casos de "violencia familiar" elevan los niveles del conflicto y provocan casos de feminicidio o actos igualmente graves hacia la contraparte o hacia terceras personas, que son generalmente otros familiares. 
3. En el ámbito jurisdiccional penal, respecto de situaciones que también tienen un elemento civil o vinculado al ámbito familiar, se puede observar lo siguiente:

i. La víctima del delito no siempre recibe una "reparación civil" (ocasionada por un proceso penal que proviene de un proceso civil, por ejemplo, en casos de divorcio a causa de atentar contra la vida del cónyuge: feminicidio) o una "indemnización".

Téngase presente que, en este punto, el fallo del sistema jurisdiccional para las víctimas produce una victimización estructuralo de segundo nivel sumamente nefasta para la legitimidad propia del sistema de impartición de justicia, porque la concepción de "justicia” no logra ser validada en la víctima o partes afectadas.

ii. La víctima no siempre observa que la "pena" impuesta es ejecutada conforme al contenido material de la sentencia, por ejemplo, en casos de aplicación de un "beneficio penitenciario" a favor del condenado.

En el ámbito jurisdiccional de familia, estos problemas se incrementan, sobre todo, cuando entre familiares se han llevado a cabo delitos y, frente al daño provocado, las relaciones familiares quedan en un contexto que afecta tanto a la víctima como a los familiares directamente involucrados con la víctima.

iii. Con respecto al seguimiento de las condiciones impuestas, en caso de determinarse una "excarcelación" por la aplicación de algún beneficio penitenciario, surge el interrogante: ¿Quién ejecuta el "seguimiento" de estos casos?

En los ámbitos del juzgamiento de delitos contra la indemnidad sexual en los que el condenado es un progenitor, las sentencias penales no suelen incluir una condición que anule la patria potestad. Esto sucede así, porque tal posibilidad no ha sido planteada ni por la víctima ni por el Ministerio Público, al centrarse el trámite del proceso en el "tema penal".

En relación con este tercer punto, que es el objeto fundamental de estudio de este texto, consideramos que el legislador y el propio contexto jurisdiccional 
no han tomado en cuenta cómo se desarrolla la "etapa postsentencia" en el ámbito de la prestación de un servicio público de tanta importancia como es la administración o impartición de justicia (Zupi \& Estruch, 2011, p. 460).

\section{El contexto posterior a la finalización del proceso judicial}

Como es evidente, el contexto temporal "postsentencia" constituye un "periodo de tiempo" sumamente importante en la evaluación del proceso judicial, porque, cuando sus fines no logran ser cumplidos, se genera un contexto mucho más conflictivo. La complejidad que se evidencia en este "periodo de tiempo" nos permite determinar los siguientes puntos de referencia:

a. Ni el Poder Judicial ni el Ministerio Público han desarrollado niveles de regulación del modo en que se evalúa del seguimiento de una sentencia judicial. Esto se evidencia en la poca fiscalización de las disposiciones a ser ejecutas por las partes procesales, lo que se debe principalmente al hecho material de la sobrecarga procesal, que, de no existir, evitaría que el "expediente resuelto" con una sentencia “deje el despacho judicial”. Esta situación hace patente la necesidad de contar con órganos jurisdiccionales de carácter administrativo que se encarguen de hacer el seguimiento de estos casos.

b. El legislador debe visualizar el contexto del conflicto desarrollado en el ámbito social, para así poder regular de una mejor manera las "normas" tanto sustantivas como procesales que se requieren. Para ello, debe tomar en cuenta también el aspecto temporal en el cual la sociedad está desarrollando sus propias condiciones, porque el Código Civil, el Código Procesal Civil, el Código Penal y otras normas referenciales no logran ser efectivas en cuanto a sus disposiciones.

c. El análisis del contexto "prejudicial" debe ser mejor evaluado por el Ejecutivo y el Congreso de la República a través del diseño de mejores políticas públicas, porque, en esencia, podrían identificarse mejores mecanismos prejudiciales de evaluación de conflictos 
sociales e interpersonales, lo que daría lugar a una mejor acción estatal en la atención de derechos y determinación de obligaciones de las partes involucradas.

Como hace evidente, surge un contexto que merece un poco más de atención para todos los involucrados en la gestión de un servicio público de tanta importancia como es la administración e impartición de justicia.

Continuar con la omisión en la evaluación de esta etapa permite pronosticar la agudización de los conflictos interpersonales en el ámbito social, lo que representa el surgimiento de contextos de mayor violencia en la sociedad, con la consecuente necesidad de la intervención oportuna del Estado, porque de lo contrario el propio sistema jurisdiccional resulta ineficaz y deslegitimado.

Continuar con una inacción ante este contexto implica favorecer el incumplimiento de las sentencias judiciales, lo que eleva los costos económicos, administrativos, humanos y logísticos del Poder Judicial y el Ministerio Público en un ámbito ajeno al jurisdiccional.

\section{La complicada relación entre valores jurídicos de tutela de derechos y valores económicos respecto del conflicto evaluado}

Previamente se revisó el ámbito "íntimo” y "privado" del conflicto propio de un contexto de crisis familiar en el que la pareja o la familia presenta un contexto de desavenencias y contradicciones sobre intereses, derechos y obligaciones, factor que da paso al contexto "público" del conflicto familiar judicializado. Estos elementos son usualmente estudiados conforme a parámetros sociolegales. En este punto se analizará el aspecto económico, en tres temas específicos.

\section{a. Evaluación en lo personal, familiar, económico y legal del conflicto}

Frente al surgimiento de una crisis en la relación de pareja o en las relaciones familiares, las personas no suelen hacer una evaluación económica $a$ priori de su situación, porque los elementos familiares, sociales y culturales 
inciden en una mayor medida frente al contexto económico. Es por ello que las defensas legales suelen asumir un elevado costo económico cuando la crisis familiar se ha judicializado.

Sin embargo, en este punto en particular, las personas asumen una situación especial que no es detectada en el ámbito jurisdiccional ni estatal: la asunción de condiciones subjetivas peyorativas, limitativas, negativas o condicionales en su propia tutela de derechos, en función de sus expectativas frente a la expareja (porque ya se generó la crisis) o frente a la familia con la cual debate una condición que genera o intereses, derechos u obligaciones.

La descripción de elementos particulares en la persona que se convierte en parte procesal no es valorada finalmente por el Poder Judicial ni el Ministerio Público, lo cual eleva los costos emocionales cuando se desarrolla el proceso y permite detallar algunas consecuencias típicas de este tipo de procesos en la jurisdicción de familia:

a. Casos de procrastinación en la tutela de derechos por afectación directa o asunción de un daño provocado por una expareja o un familiar.

b. Casos de procrastinación en la defensa de un interés o de un derecho a favor de una persona en situación de dependencia (económica, moral o física) respecto de las obligaciones de una expareja o un familiar.

Esta situación es explicada por cada parte procesal en la argumentación de sus fundamentos de hecho en la demanda o contestación de una demanda y lamentablemente no son observados por los magistrados.

\section{b. Evaluación legal, económica y familiar implicada por la participación en el sistema jurisdiccional}

En este ámbito, las partes en conflicto ya se convierten en partes procesales, superando el contexto íntimo y privado de la etapa inicial de la crisis familiar. Este punto se representa en el contexto jurisdiccional, cuando las partes procesales ejecutan actos procesales específicos, los cuales son de un carácter negativo para sus propios derechos e intereses: 
a. Casos de abandono procesal

b. Casos de negligencia en la defensa procesal

c. Casos de inejecución de una sentencia favorable

La mejor representación de lo detallado se observa en el contexto del seguimiento de procesos de alimentos, en el que las partes demandantes que han obtenido una victoria judicial no logran el cumplimiento de sus derechos o los de una persona dependiente y, ante la elevada condicionalidad para poder desarrollarlos, optan por desarrollar un acto procesal contrario a sus intereses y derechos.

\section{c. Desvinculación de una evaluación de costos en el sistema jurisdiccional}

Tanto el Poder Judicial como el Ministerio Público no han tomado en cuenta el verdadero "costo" que implica la ejecución y evaluación de un expediente judicial. Tal evaluación en lo económico y en lo temporal podría ser sumamente positiva en una reformulación de una gestión institucional jurisdiccional, porque permitiría "observar" los aspectos siguientes:

a. El elevado costo logístico que implica mantener y sostener las instalaciones de las entidades jurisdiccionales.

b. El elevado costo económico que implica abonar las remuneraciones de magistrados, personal jurisdiccional y personal administrativo en el Poder Judicial y el Ministerio Público.

c. El elevado costo logístico que implica prestar atención a cada requerimiento del sistema en el trámite de un expediente judicial.

d. El análisis disfuncional del mismo sistema judicial en el ámbito de la atención de conflictos familiares, en los que las "dos partes procesales" pueden intervenir en varios expedientes judiciales, en función a la opción que les otorga la ley, con lo cual se genera la "atomización" de procesos judiciales.

Sobre estos puntos esenciales, podemos señalar que la atención de un expediente sobre una violación sexual o un delito de peculado ostenta el mismo 
costo que la atención de un caso de alimentos o de violencia familiar. Como se podrá observar, este problema hace que el sistema jurisdiccional no pueda atender sus propias necesidades, lo cual configura un error, sobre todo, de gestión institucional.

\section{La víctima ante el contexto penal}

En el ámbito penal, la situación tampoco logra tener un panorama positivo en una evaluación general, principalmente porque se pueden ubicar cuatro elementos que cuestionan la legitimidad del Estado en el ámbito de la prestación de servicios vinculados a la administración e impartición de justicia.

\section{a. La privatización del derecho penal}

A raíz de las reformas del proceso penal, es posible identificar el paso del sistema inquisitivo de la jurisdicción penal a un modelo acusatorio (Armenta Deu, 2012), en el que la característica básica es la oralización del proceso penal. Esto incide en la búsqueda de una mayor celeridad procesal y en la atención a las garantías procesales y a los derechos de la víctima con mayor eficiencia por parte del servicio público.

Sin embargo, las críticas parten de que esta reforma no ha logrado atender eficientemente a las víctimas por factores como
a. La terminación anticipada del proceso,
b. El principio de oportunidad,
c. La conclusión anticipada del proceso y
d. El proceso inmediato.

Estos factores constituyen elementos procesales favorables al sujeto activo del delito, quien accede a una situación ventajosa frente al proceso, pese a tener una condición de culpabilidad, la cual resulta manifiestamente contraria a sus intereses.

\section{b. La percepción de la condena por parte de la víctima o sus familiares}

Lamentablemente la víctima no logra visualizar la situación que genera una sentencia condenatoria en contra de quien le generó una ofensa a alguno 
de sus derechos e intereses, principalmente porque el "daño" supera todo punto de evaluación jurídico, al extenderse a un contexto moral, social, económico y familiar.

La diferenciación de estos contextos permite identificar que la "víctima" varía en función de diferentes elementos evaluativos, como los siguientes:

a. Su rango de edad.

b. El delito cometido. Es totalmente diferente la "afectación" de la víctima en casos de delitos contra el patrimonio y en casos en los que se afecta la indemnidad sexual.

c. Su propia supervivencia, dado que terceras personas pueden asumir el rol de víctimas o de representación de la víctima, como ocurre en los casos de homicidios.

d. El nivel de afectación provocado por el delito respecto de su proyección temporal: lucro cesante, daño moral, incapacidad física, etc.

Como se puede observar, la condena no logra ser un elemento positivo en la percepción de la víctima, punto que no ha logrado comprender el sistema judicial, principalmente por la incapacidad del legislador de visualizarlo.

\section{c. La cuantificación de la reparación civil}

Este aspecto está vinculado al contexto de la racionalidad de la decisión judicial. La cuantificación de la reparación civil es cuestionada severamente por la víctima, porque no logra tener un mínimo de fundamentación. Se observan métodos de validación de una decisión judicial tan diferentes entre sí que resulta disfuncional la misma sentencia, principalmente porque se cuestiona el mecanismo argumentativo de la cuantificación de la reparación civil.

El juez penal no logra tener los mismos elementos evaluativos que el juez civil y por ello la reparación civil no forma parte del esquema ordinario en la fundamentación de la sentencia, con lo cual queda ubicada en un nivel terciario frente a la "evaluación de la responsabilidad" y la "condena" impuesta. Este es un defecto sobre el cual la doctrina penal no ha logrado generar un mayor esfuerzo, porque la condena y la responsabilidad penal son los elementos excluyentes en la labor jurisdiccional penal. 


\section{d. Los beneficios penitenciarios del condenado frente a la víctima o sus familiares}

Una vez que es emitida la sentencia, el condenado puede acceder a determinados beneficios penitenciarios que no logran ser admitidos o aceptados por la víctima, pero esta no tiene legitimidad para ejecutar alguna acción procesal, porque la ley no lo permite.

En este punto, inclusive el incumplimiento de una reparación civil no logra ser óbice para que el delincuente tenga acceso a un beneficio penitenciario, porque de por medio está la obligación estatal de brindar los mecanismos suficientes y necesarios para su rehabilitación.

\section{Conclusiones}

En una evaluación general, se evidencia que la actividad jurisdiccional resulta deficiente, lo cual se amplifica cuando se analizan dos situaciones particulares: los conflictos familiares judicializados, vinculados al contexto de la violencia familiar, y los casos relacionados con la corrupción en la administración pública, principalmente porque el Estado no asume un verdadero rol de parte afectada en la comisión de un delito en relación con la afectación económica institucional y social (Corcione Nieto et al., 2019).

Este panorama genera el incremento de la poca legitimidad de la función judicial, que incide en el ámbito democrático y de gobernabilidad en una nación, situación que es descrita por Parra Quijano (2000, p. 157) como un hecho acreditado por la poca intervención del Estado en la sociedad. Se trata de un defecto institucional que no toma en cuenta la verdadera importancia de la evaluación del conflicto humano en el ámbito jurisdiccional, porque los conflictos familiares y penales generan un contexto particular y diferenciado de los conflictos puros (procesos civiles) (Barrero-Barrero \& Baquero-Valdés, 2020).

\section{Referencias}

Armenta Deu, T. (2012). Sistemas procesales penales: la justicia penal en Europa y América ¿Un camino de ida y vuelta? Marcial Pons. 
Barrero-Barrero, D., \& Baquero-Valdés, F. (2020). Objetivos de Desarrollo Sostenible: un contrato social posmoderno para la justicia, el desarrollo y la seguridad. Revista Cientifica General José María Córdova, 18(29), 113-137. http://dx.doi.org/10.21830/19006586.562

Corcione Nieto, M. A., Fernández-Osorio, A. E., Cabrera-Cabrera, L. J., \& Rojas Yaima, B. C. (2019). Aportes de la Academia a legitimidad de la justicia en Colombia. Revista Cientifica General José María Córdova, 17(28), 819-843. https://doi.org/10.21830/19006586.516

López, R., \& Pérez, A. (2004). Tendencias actuales en el derecho de familia. Universidad de Almería.

Miron, M. (2019). Counterinsurgency operations in the 21st Century: Insights from the U.S. Army Experiences in Iraq. Escuela Militar de Cadetes "General José María Córdova".

Miron, M. (2019b). Counterinsurgency theory and practice: From Early Renaissance to present day. Escuela Militar de Cadetes "General José María Córdova”. https://doi. org/10.21830/9789585200890

Parra Quijano, J. (2000). Mecanismos alternativos de resolución de conflictos. En C. Latorre, \& M. Morán, Estudios sobre evaluación de procesos de reforma de la Justicia en Iberoamérica. Ministerio de Justicia.

Peña, C., Sierra-Zamora, P. A., \& Hoyos, J. C. (2019). La política de fronteras de Colombia ante las nuevas amenazas de seguridad y defensa. Revista Cientifica General José María Córdova, 17(28), 773-795. https://doi.org/10.21830/19006586.473

Pérez del Blanco, G. (2003). La ejecución forzosa de sentencias en el orden jurisdiccional contencioso-administrativo: doctrina y formularios. León, Del Blanco.

Pérez Martín, A. (2009). La ejecución de las resoluciones dictadas en procesos de familia. Lex Nova.

Quintero Cordero, S. (2020). Seguridad ciudadana y participación de las comunidades en América Latina. Revista Cientifica General José María Córdova, 18(29), 5-24. http:// dx.doi.org/10.21830/19006586.561

Rodríguez Boente, S. (2003). La justificación de las decisiones judiciales: el artículo 120.3 de la Constitución española. Universidad de Compostela.

Zupi, M., \& Estruch, E. (2011). Desafios de la cohesión social en tiempos de crisis: diálogo EuroLatinoamericano. Universidad Complutense de Madrid. 